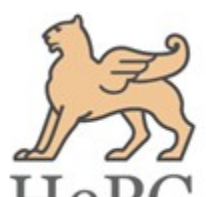
HePG

ISSN: 2348-1900

Plant Science Today

http://www.plantsciencetoday.online

\title{
Phytotherapy: Herbal medicine in the management of Diabetes mellitus
}

\author{
Twinkle S. Bansode ${ }^{1^{*}}$ and B. K. Salalkar ${ }^{2}$ \\ ${ }^{1}$ Pravara Institute of Medical Sciences (DU), Loni (Bk), Tal.Rahata, Dist.Ahmednagar, (MS), 413736, India \\ ${ }^{2}$ Arts, Science and Commerce College, Rahata, Tal-Rahata, Dist. Ahmednagar (MS), 423107, India
}

Article history

Received: 08 September 2017 Accepted: 30 September 2017 Published: 15 October 2017

C Bansode and Salalkar (2017)

Editor

Afroz Alam

\section{Publisher}

Horizon e-Publishing Group

\section{Correspondence}

Twinkle S. Bansode

战inklejournal@gmail.com

\begin{abstract}
Despite considerable progress in the treatment of the diabetes with synthetic drugs, the search for effective, safe and inexpensive drugs is ongoing from herbs, since they offer a wide range of antidiabetic agents. Antidiabetic studies using in silico, in vitro and in vivo aspect of different medicinal plant products (Trigonella foenum-graecum, seeds; Syzygium cumini, seeds; Salvadora persica, leaves and Terminalia chebula, seeds) were reviewed. The objective of the study was to compare these medicinal plants for their hypoglycemic effect and phytochemical composition in order to find out most feasible and efficient antidiabetic agent. In this regard, the article is going to look at the phytochemical profile and the antihyperglycaemic properties and toxicity studies of the various fractions isolated from these plants. Studies claimed that all crude as well as partially purified fractions showed an antidiabetic effect hence are potent antidiabetic agents, but maximum effect observed in case of fraction isolated from Syzygium cumini and Salvadora persica.
\end{abstract}

\section{Keywords}

Diabetes mellitus; Trigonella foenum-graecum; Syzygium cumini; Salvadora persica; Terminalia chebula.

\section{Citation}

Bansode T S, Salalkar B K. Phytotherapy: Herbal medicine in the management of Diabetes mellitus. Plant Science Today 2017;4(4):161-165. doi: 10.14719/pst.2017.4.4.347

\section{Introduction}

Diabetes mellitus (DM), a condition of persistent hyperglycemia with rising prevalence (accounts for $>95 \%$ of diabetes ceases worldwide) all over the world. It is caused either by inadequate insulin secretion from pancreatic beta cells or by the insufficient utilization of insulin or both (1). Hyperglycemia triggers the generation of Reactive oxygen species (ROS) and autoxidation of glucose leading to domination of the condition of oxidative stress. Hyperglycemia also causes tissue damage through different mechanisms, including increased intracellular formation of advanced glycation end products (AGEs), increased expression of the receptor for AGEs, activation of protein kinase C isoforms etc. $(2,3)$. According to the International Diabetes Federation, it is estimated that 415 million people of the world's population were suffering from DM in 2015 and it is expected to show a steady growth of 642 million by the year of 2040 (4). Hence 
efforts are to be taken to control the diabetes. Today, the synthetic drugs used for the treatment of hyperglycemia like acarbose, miglitol and voglibiose, sulphonylureas, biguanides, are associated with various side effects and are effective at higher doses (5). Therefore, researchers focus on an alternative medicine system that reduces the major medical issues in the management of diabetes. Traditional herbal medicines are getting significant attention because of their effectiveness, less side effects and relatively low cost (5).

Application of blood glucose-lowering agents is the most common strategy used in the management of diabetes. Phytochemicals being no adverse effect are the fundamental source of lead candidate that can prove as an effective antidiabetic agent. These are obtained from herbal preparations and are abundant in nature with lower cost (6). It is found in the literature that total 108 plant species belonging to 56 families with antidiabetic activity (7). This review article encompasses various comparative analysis of the four plants Trigonella foenum-graecum L., Syzygium cumini (L.) skeels, Salvadora persica L., Terminalia chebula Retz. using different aspects.

\section{Target Identification}

Target identification is an identification of known bioactive targets for chemical compounds that maps compound structures in chemogenomical space in order to predict the biological targets. Molecular docking of a compound is one of the widely used methods to determine the potential partner of the proteins in silico (8). Past research $(9,10,11)$ analyzed the phytochemicals reported in these four plants for their binding affinity towards the enzymes those plays an important role in the management of diabetes. Five enzymes viz. alpha amylase, beta glucosidase, glucokinase, glycogen synthase kinase $3 \beta$ and alpha glucosidase were targeted for this purpose. Molecular docking analysis was done using Autodock module available in PyRx version 8. The best docked compounds were considered as potential antidiabetic phytochemicals as they interact and modulate the action of enzymes favorably (Table 1).

Though Diosgenin reported in Trigonella foenum-graecum found to be the most potent antidiabetic agent in silico with high binding energy $-8.5 \mathrm{kcal} / \mathrm{mol}$, its effect is limited to the enzyme glycogen synthase kinase $3 \beta$ when compared to other three phytochemicals i.e. Luteolin from $T$. chebula, Ellagic acid from Syzygium cumini, and Kaempferol from Salvadora persica. Two phytochemicals Ellagic acid and Kaempferol are the best lead candidates as their activity is not limited to a single enzyme. Both the compounds have reasonable binding energy and effectively interact with the all five enzymes studied. The Kaempferol has been reported for its nephro-protective efficiency of injured tissue resulted from mercuric chloride $(\mathrm{HgCl} 2)$ induced nephrotoxicity in a rat model (12). It also acts as anti-migration reagent in human pancreatic cancer cells that help reduce malignant pancreatic cancer (13). Ellagic Acid, a dietary Polyphenol was found to have a selective cytotoxic effect on HSC-2 Oral Carcinoma Cells, but not on normal gingival fibroblast cells (14). A Glutathione S-transferase (GST) enzyme is helpful in detoxification of carcinogens and in reduction of carcinogeninduced mutagenesis and tumorigenesis. Barch et al., 1995 stated that ellagic acid induces transcription of the rat glutathione S-transferaseYa gene (15).

\section{Screened plant extracts possess diverse biologically active substances}

The potential of plants for hypoglycemic effects was studied using in vitro models. Several studies, $(9,10,11,16)$ compared hypoglycemic potential of four fractions i.e. petroleum ether, chloroform, ethanol, aqueous for each individual plant and extract with highest potential were selected for further analysis suggesting that these fractions contain bioactive principles in respective plants (Table1). The in vitro model selected for analysis was the inhibitory activity assay of a carbohydrate digesting enzyme, alpha amylase. In the assay, various concentrations of the plant fractions as well as standard drug $100 \mu \mathrm{g} / \mathrm{ml}, \quad 200 \mu \mathrm{g} / \mathrm{ml}$, $400 \mu \mathrm{g} / \mathrm{ml}, 600 \mu \mathrm{g} / \mathrm{ml}, 800 \mu \mathrm{g} / \mathrm{ml}$ and $1000 \mu \mathrm{g} / \mathrm{ml}$, were prepared. The result revealed that the inhibitory activity of plant fractions and standard drug, increases linearly showing a significant effect on the concentration of $1000 \mu \mathrm{g} / \mathrm{ml}$. It is clear that the chloroform fraction of fenugreek, an ethanol fraction of $S$. cumini, aqueous fraction of $S$. persica and petroleum ether fraction of $T$. chebula has the highest antidiabetic potential than other fractions compared. The further bioactive compounds from these fractions was identified by using the Thin Layer Chromatography (TLC) Technique and confirmed by respective confirmatory tests.

All the fractions gave best alpha amylase inhibitory activity in a dose dependent manner. Ethanol fraction isolated from $S$. cumini and aqueous fraction isolated from S. persica showed a significant value for the alteration of carbohydrate metabolizing enzyme at very lower doses of $374 \mu \mathrm{g} / \mathrm{ml}$ and $376 \mu \mathrm{g} / \mathrm{ml}$ respectively. Other fractions also found effective, but at very high doses. It is clear from the in vitro studies that antidiabetic activity of all fractions is due to the presence of phytochemicals present in it. Phytochemical analysis of the bioactive fractions is shown in Table1.The study revealed that the chloroform fraction of $T$. foenum-graecum contains alkaloids, phenolics, saponins, tannins, steroids fatty acids; ethanol fraction of S. cumini contains alkaloids, phenolics, flavonoids, saponins, tannins, terpenoids, steroids, fatty acids, coumarins, 
Table1: Different aspects of antidiabetic studies

\begin{tabular}{|c|c|c|c|c|}
\hline Output & $\begin{array}{l}\text { Trigonella foenum- } \\
\text { graecum }\end{array}$ & Syzygium cumini & Salvadora persica & $\begin{array}{l}\text { Terminalia } \\
\text { chebula }\end{array}$ \\
\hline Family & Fabaceae & Myrtaceae & Salvadoraceae & Combretaceae \\
\hline \multicolumn{5}{|c|}{ In silico } \\
\hline $\begin{array}{l}\text { Best Docked } \\
\text { phytochemical }\end{array}$ & Diosgenin & Ellagic acid & Kaempferol & Luteolin \\
\hline \multicolumn{5}{|c|}{ In vitro } \\
\hline Plant part used & Seeds & Seeds & Leaves & Seeds \\
\hline $\begin{array}{l}\text { Extract showing } \\
\text { highest antidiabetic } \\
\text { activity }\end{array}$ & Chloroform & Ethanol & Aqueous & Petroleum ether \\
\hline IC50 ( $\mu \mathrm{g} / \mathrm{ml})$ & 1622 & 374 & 376 & 1115 \\
\hline $\begin{array}{l}\text { Phytochemical } \\
\text { present in } \\
\text { respective extract }\end{array}$ & $\begin{array}{l}\text { alkaloids, phenolics, } \\
\text { saponins,tannins, } \\
\text { steroids fatty acids }\end{array}$ & $\begin{array}{l}\text { alkaloids, phenolics, } \\
\text { flavonoids, } \\
\text { saponins, tannins, } \\
\text { terpenoids, steroids, } \\
\text { fatty acids, } \\
\text { coumarins, } \\
\text { anthocyanins }\end{array}$ & $\begin{array}{l}\text { alkaloids, phenolics, } \\
\text { flavonoids, saponins, } \\
\text { steroids, } \\
\text { coumarins quinines }\end{array}$ & $\begin{array}{l}\text { alkaloids, } \\
\text { flavonoids, } \\
\text { saponins, tannins, } \\
\text { terpenoids, steroids, } \\
\text { fatty acids }\end{array}$ \\
\hline Bioactive compound & Saponin & Tannin & Flavonoid & Flavonoid \\
\hline References & (9) & (10) & (11) & (6) \\
\hline
\end{tabular}

anthocyanins; aqueous fraction of $S$. persica contains alkaloids, phenolics, flavonoids, saponins, steroids, coumarins and quinines while petroleum ether fractions of $T$. chebula contains alkaloids, flavonoids, saponins, tannins, terpenoids, steroids, fatty acids. Considering that one of these phytochemical is responsible for highest peak of activity we have further partially purified the bioactive compound using the TLC method. It was confirmed by the analysis that a petroleum ether fraction of fenugreek contains saponins as a bioactive compound; the antidiabetic activity of $S$. cumini is due to the presence of tannins, while $S$. persica and $T$. chebula are rich in flavonoids that make them to become a better antidiabetic agent (17). According to Gupta et al., $(18,19)$ low hemoglobin concentration in blood as well as high blood glucose concentration in the blood are the two factors associated with diabetic profile. Therefore the fractions were also checked for the said parameters. The partially purified fractions caused a reduction in the blood glucose level, total cellular content and free hemoglobin in supernatant at lower doses in case of lysed diabetic human whole blood samples. The decreased glucose level in, lysed diabetic human whole blood, clearly showed the antihyperglycaemic effect of these fractions and justify the claim of the traditional healers (17). All four factions purified are reported to have significance in diabetes management. Saponin regulates the plasma glucose level and prevents diabetic complications due to their antioxidant property. The hypotriglyceridemic and hypocholesterolemic properties of saponins help reduce the risk of atherosclerosis in diabetic patients. Obesity caused due to side effect of antidiabetic drugs can be cured by saponins by reducing body fat (20). Tannins, especially hydrolyzable tannins have a key role in diabetes as they induce glucose transport through activation of the insulin-mediated signaling pathway in adipocytes (21). Flavonoids exerts antidiabetic action by providing various mechanisms of actions, including modulatory effects on the blood sugar transporter, by enhancing insulin secretion, reducing apoptosis and promoting the proliferation of pancreatic $\beta$ cells, reducing insulin resistance, inflammation and oxidative stress in muscle and promoting translocation of GLUT4 via PI3K/AKT and AMPK pathways etc. (22).

\section{Natural Saponins, Tannins and Flavonoids acts as hypoglycemic agents}

In the previous work, (Bansode et. al., in press) partially purified bioactive compounds were further investigated for its effect on blood glucose level in rat models. For this, diabetes was induced in male Albino Wistar rat models weighing 150 $250 \mathrm{~g}$ with a single intraperitoneal administration 
of alloxan $125 \mathrm{mg} / \mathrm{kg}$ body weight and treated with $100 \mathrm{mg} / \mathrm{kg}$ of partially purified bioactive fractions. Glibenclamide was used as a positive control. The experimental protocols and procedures used in this study were approved by the Institutional Animal Ethics Committee under strict compliance of the Committee for the Purpose of Control and Supervision of Experiments on Animals (CPCSEA) guidelines. Blood glucose, liver glycogen and body weight were studied up to $15^{\text {th }}$ day.

Partially purified bioactive fractions, when subjected to in vivo study proved best. It was observed that diabetic rats treated with partially purified flavonoid fraction isolated from S. persica and tannin fraction isolated from $S$. cumini shown a significant $(p<0.05)$ decrease in serum glucose and an increase in body weight and liver glycogen in alloxan induced rat models, in comparison with other partially purified compound. The toxicity studies of all four partially purified fractions have revealed no visible signs or symptoms of toxicity in normal rats. Hence, with all data recorded and analyzed, this study concludes that the partially purified bioactive fractions can make for an efficient and effective alternate complementary medicine in the management of diabetes mellitus.

\section{Conclusion}

After careful review of several relevant papers on the subject, we have concluded that phytochemicals isolated from four plants viz. Trigonella foenum-graecum (Fenugreek), Syzygium cumini (Jambul), Salvadora persica (Miswak) and Terminalia chebula (Hirda) possess and showed potent antidiabetic activity by various mechanisms of actions such as altering the activity of enzymes useful in diabetes management, inhibiting alpha amylase inhibitory activity thereby reducing the blood glucose level, total cellular content etc. Out of these flavonoids isolated from S. persica and tannin isolated from $S$. cumini was more potent than any other partially purified fraction. Hence, was selected for further purification and quantification in order to determine the actual specific compounds responsible for observed antidiabetic potential.

\section{Competing interests}

The authors declare that they have no competing interests.

\section{Authors contributions}

Both authors contributed equally to prepare the mini review article.

\section{Acknowledgements}

The authors are grateful to Pravara Institute of Medical Sciences, Deemed University for providing the support. Reviewers and editor of the article are also greatly acknowledged for their tremendous effort in reviewing the manuscript.

\section{References}

1. Gurusamy N. Mini review: The potential of Mesenchymal Stem Cells in diabetes mellitus. Diabesity 2017; 3(1): 1-4. doi: 10.15562/diabesity.2017.37

2. Chen M, Yan X, Chen Y, Zhao C. Phytochemicals for Non-insulin Diabetes Mellitus: A Minireview on Plant-Derived Compounds Hypoglycemic Activity. Journal of Food and Nutrition Sciences 2017; 5 (2):23-27. doi: 10.11648/j.jfns.20170502.11

3. Tiwari B K, Pandey K B, Abidi A B, Rizvi S I. Markers of oxidative stress during diabetes mellitus. Journal of Biomarkers 2013; 2013:1-9. doi: 10.1155/2013/378790

4. Ogurtsova K, da Rocha Fernandes J D, Huang Y, Linnenkamp U, Guariguata L, Cho N H, Cavan D, Shaw J E, Makaroff L E. IDF Diabetes Atlas: Global estimates for the prevalence of diabetes for 2015 and 2040. Diabetes Research and Clinical Practice 2017; 128:40-50. doi: 10.1016/j.diabres.2017.03.024

5. Samyal M L, Ahuja A, Ahmed Z. Evaluation of Antidiabetic Activity of Isolated Compound from Ougeinia oojeinensis Bark Extract in Diabetic Rats. UK Journal of Pharmaceutical and Biosciences 2014;2(5):27-33. doi: 10.20510/ukjpb/2/i5/91121

6. Singab A N, Youssef F S, Ashour M L. Medicinal plants with potential antidiabetic activity and their assessment. Medicinal Aromatic Plants 2014; 3 (1):1-12.

7. Mamun-or-Rashid A N, Hossain M S, Hassan B N, Dash M K, Sapon A, Sen M K. A review on medicinal plants with antidiabetic activity. Journal of Pharmacognosy and Phytochemistry 2014; 3(4):149-59.

8. Wang L, Ma C, Wipf P, Liu H, Su W, Xie X Q. TargetHunter: an in silico target identification tool for predicting therapeutic potential of small organic molecules based on chemogenomic database. The AAPS journal 2013; 15(2):395-406. doi: 10.1208/s12248-012-9449-Z

9. Bansode T S, Gupta A G, Chaphalkar S R, Salalkar $\mathrm{B}$ K. Integrating in-silico and in-vitro approaches to screen the antidiabetic drug from Trigonella foenum graecum Linn.International Journal of Biochemistry Research \& Review 2016;14(3): 1-10. doi: 10.9734/IJBCRR/2016/29875

10. Bansode T S, Gupta A G, Salalkar B K. In silico and in vitro assessment on antidiabetic efficacy of secondary metabolites from Syzygium cumini (L.) Skeels. Plant Science Today 2016; 3 (4):360367. doi: 10.14719/pst.2016.3.4.264

11. Bansode T S, Salalkar B K. Exploiting the therapeutic potential of secondary metabolites from Salvadora persica for diabetes using in silico and in vitro approach. Journal of Life Science and Biotechnology 2016;5: 127-136.

12. Vijayaprakash S, Langeswaran K, Kumar S G, Revathy R, Balasubramanian M P. Nephroprotective significance of kaempferol on mercuric chloride induced toxicity in Wistar albino rats. Biomedicine \& Aging Pathology 2013; 3 (3):119-24. doi: 10.1016/j.biomag.2013.05.004 
13. Lee J, Kim J H. Kaempferol inhibits pancreatic cancer cell growth and migration through the blockade of EGFR-related pathway in vitro. PloS One 2016; 11 (5):e0155264. doi: 10.1371/journal.pone.0155264

14. Weisburg J H, Schuck A G, Reiss S E, Wolf B J, Fertel S R, Zuckerbraun H L, Babich H. Ellagic acid, a dietary polyphenol, selectively cytotoxic to HSC-2 oral carcinoma cells. Anticancer research.2013; 33 (5):1829-36.

15. Barch D H, Rundhaugen L M, Pillay N S. Ellagic acid induces transcription of the rat glutathione S-transferase-Ya gene. Carcinogenesis 1995; 16 (3):665-8. doi: 10.1093/carcin/16.3.665

16. Bansode T S, Salalkar B K. Strategies in the design of antidiabetic drugs from Terminalia chebula using in silico and in vitro approach. MicroMedicine 2016; 4 (2): 60-67.

17. Bansode T S, Gupta A, Shinde B, Salalkar B K. Partial purification and antidiabetic effect of bioactive compounds isolated from medicinal plants. MicroMedicine 2017; 5 (1): 1-7.
18. Gupta A, Chaphalkar S R. Haemolytic activities and anti-diabetic effect of Terminalia arjuna and Emblica officinalis. European Journal of Pharmaceutical and medical research 2016; 3 (6):334-338.

19. Gupta A, Chaphalkar S R. Antidiabetic activity of Calotropis gigantea in human whole blood. Journal of Disease and Global Health 2016; 6(3): 107-112.

20. Elekofehinti O O. Saponins: Anti-diabetic principles from medicinal plants-A review. Pathophysiology 2015; 22(2):95-103. doi: 10.1016/j.pathophys.2015.02.001

21. Liu X, Kim J K, Li Y, Li J, Liu F, Chen X. Tannic acid stimulates glucose transport and inhibits adipocyte differentiation in 3T3-L1 cells. The Journal of nutrition 2005; 135(2):165-171.

22. Vinayagam $\mathrm{R}, \mathrm{Xu} \mathrm{B}$. Antidiabetic properties of dietary flavonoids: a cellular mechanism review. Nutrition \& metabolism 2015; $12(1): 60$. doi: 10.1186/s12986-015-0057-7 